AperTO - Archivio Istituzionale Open Access dell'Università di Torino

\title{
Work, pensions and transgenerational justice
}

\section{This is a pre print version of the following article:}

Original Citation:

\section{Availability:}

This version is available http://hdl.handle.net/2318/1726589

since 2020-02-07T15:33:25Z

Publisher:

Routledge

Terms of use:

Open Access

Anyone can freely access the full text of works made available as "Open Access". Works made available under a Creative Commons license can be used according to the terms and conditions of said license. Use of all other works requires consent of the right holder (author or publisher) if not exempted from copyright protection by the applicable law. 


\section{T\&F PROOFS NOT FOR DISTRIBUTION}

\section{Law, Labour and the Humanities}

The ontology of work and the economics of value underpin the legal institution, with the existence of modern law predicated upon the subject as labourer.

In contemporary Europe, labour is more than a mere economic relationship. Indeed, labour occupies a central position in human existence: since the industrial revolution, it has been the principal criterion of reciprocal recognition and of universal mobilization. This multi-disciplinary volume analyses labour and its depictions in their interaction with the latest legal, socio-economic, political and artistic tendencies. Addressing such issues as deregulation, flexibility, de-industrialization, the pervasive enlargement of markets, digitization and virtual relationships, social polarisation and migratory fluxes, this volume engages with the existential role played by labour in our lives at the conjunction of law and the humanities.

This volume will be of interest to law students, legal philosophers, theoretical philosophers, political philosophers, social and political theorists, labour studies scholars, literature and film scholars.

Tiziano Toracca is a literary scholar, Visiting Professor at the Department of Literary Studies, Gent University and Research Fellow at the University of Torino.

Angela Condello is a legal philosopher, Adjunct Professor and Research Fellow at the University of Torino, the Principal Investigator of a Jean Monnet Module and the Director of LabOnt Law. 


\section{T\&F PROOFS NOT FOR DISTRIBUTION}

\section{Discourses of Law}

series editors

Peter Goodrich, Benjamin N. Cardozo School of Law, USA

Michel Rosenfeld, Benjamin N. Cardozo School of Law, USA

Arthur Jacobsen, Benjamin N. Cardozo School of Law, USA

The publisher gratefully acknowledges the support of the Jacob Burns Institute for Advanced Legal Studies of the Benjamin N. Cardozo School of Law to the series Discourses of Law.

A GlassHouse Book

for information about the series and details of previous and forthcoming titles, see https://www.routledge.com/Discourses-of-Law/book-series/SE1036 


\title{
T\&F PROOFS NOT FOR DISTRIBUTION
}

\section{Law, Labour and the Humanities}

\section{Contemporary European Perspectives}

\section{Edited by}

Tiziano Toracca and Angela Condello

\author{
Routledge \\ Taylor \& Francis Group




\section{T\&F PROOFS NOT FOR DISTRIBUTION}

First published 2020

by Routledge

2 Park Square, Milton Park, Abingdon, Oxon OXI4 4RN

and by Routledge

52 Vanderbilt Avenue, New York, NY 10017

Routledge is an imprint of the Taylor \& Francis Group, an informa business

(c) 2020 selection and editorial matter, Tiziano Toracca and Angela Condello; individual chapters, the contributors

The right of Tiziano Toracca and Angela Condello to be identified as the authors of the editorial material, and of the authors for their individual chapters, has been asserted in accordance with sections 77 and 78 of the Copyright, Designs and Patents Act 1988.

All rights reserved. No part of this book may be reprinted or reproduced or utilised in any form or by any electronic, mechanical, or other means, now known or hereafter invented, including photocopying and recording, or in any information storage or retrieval system, without permission in writing from the publishers.

Trademark notice: Product or corporate names may be trademarks or registered trademarks, and are used only for identification and explanation without intent to infringe.

A Glasshouse Book

British Library Cataloguing-in-Publication Data

A catalogue record for this book is available from the British Library

Library of Congress Cataloging-in-Publication Data

A catalog record has been requested for this book

ISBN: 978-0-367-077I7-4 (hbk)

ISBN: 978-0-429-02230-2 (ebk)

Typeset in Galliard

by Taylor \& Francis Books 


\title{
T\&F PROOFS NOT FOR DISTRIBUTION
}

\section{Chapter 2}

\section{Work, pensions and transgenerational justice}

\author{
Tiziana Andina
}

\section{Labor market $\mathbf{4 . 0}$}

We have been promised happiness, freedom and emancipation: things that humans, at least in theory, aspire to. Freedom from invasive physical constraints (which would also create emancipation) and freedom from many manual arduous jobs that would be replaced by machines and artificial intelligence. Technological development would facilitate mobility and speed, freeing us from having to perform the most strenuous and exhausting tasks. Lastly, artificial intelligence would work hand in hand with natural intelligence, and humans would think more and work less. The overall vision or, in any case, the positive narrative of this project, sees technological development as a fundamental tool to achieve the net improvement of people's quality of life. And yet, as history shows, things didn't quite go as expected.

The promise of happiness offered by technological development, for instance, was kept only to a small extent because, as often happens, things have taken an unexpected turn. Consider wealth, for example: if it is true that new wealth has been produced, it is equally true that its redistribution has been minimal and certainly not sufficient. Moreover, in a world that is largely globalized and extremely sophisticated in terms of technology, complexity ends up being the element that characterizes the social structure and dynamic in decisive ways. Culture and education are probably the only really useful tools to effectively navigate in contexts of this kind. Now, it's not a bad thing if human beings must invest in their culture in order to really be able to dominate the complexity that surrounds them. Likewise, it's not a bad thing if the less sophisticated jobs are gradually outsourced to machines in societies 4.0. After all, machines do not get tired, they are subject to less "wear and tear" than human beings, they do not protest for low wages, they generally do not get sick and are rarely replaced. In other words, they are highly performing and economically advantageous objects: they do not get tired, they can work non-stop, they are not subject to irritability or mood swings and they die differently from human beings.

In this situation two things have progressively emerged: firstly, that human beings often resist their improvement due to their natural disposition or because 


\section{T\&F PROOFS NOT FOR DISTRIBUTION}

\section{Tiziana Andina}

the social condition makes this process particularly burdensome for them. Secondly, that the result of this resistance has led, in many circumstances, to a worsening of social inequality, since the gap between prestigious, well-paid intellectual jobs on the one hand and precarious, poorly paid and manual jobs on the other hand has not only grown but has also given way to a process of progressive desertification of the human factor. In fact, machines are gradually replacing human beings, so those who wish to carry out work with a low intellectual content often find it impossible to do so, as they are replaced by better performing and more efficient machines.

And there is a second point worth considering: the serious risk of precarization that new generations have been facing for over fifteen years now. In a highly competitive world, in which people and things move in very short times and in which industrial production is able to reach very high numbers, the price of the transformation of production cycles has often been paid by workers. Apart from a few exceptions that, not coincidentally, play the role of monopolists or semimonopolists in the reference market, most companies produce based on the market's demand. The workers, therefore, are often considered functional for the purpose, i.e. to meet a given production threshold or the objectives set by the market. Therefore, companies usually identify a fixed quota of people who support production on a permanent basis and who represent the main structure of the company, and then a variable quota that is asked to work only in case of need. This latter quota of workers is destined either to be kept precariously in view of a potential increase of demand, or to be dismissed when the demand drops.

The significant fact from the scientific point of view, which is very upsetting from the point of view of social balance, is that the share of precarious workers is becoming ever wider. This is true in both the private and the public sectors. To give an idea of how paradoxical the situation is, it will suffice to mention a typical Italian real-life case: it involves Federica, Alessandra, Laura and Andrea, ${ }^{1}$ who for some time have "worked" for the National Library of Rome, the largest Italian library. The fact that they worked for the National Library means that they were entrusted with the tasks that are normally entrusted to a librarian. Nevertheless - i.e. despite the fact that they were workers who performed completely normal tasks - the institution treated them as phantom workers. In fact, they worked without being recognized either from an economic point of view - the remuneration was not the standard one in the sector either as regards the agreed minimum wage, or as to the methods of payment - or from a social point of view. They were not considered workers, but rather volunteers.

All of them, in fact, were not formally public employees, although they worked for the public sector. In fact, they weren't even employees - indeed, looking closer, they weren't even workers. As shown by the journalistic investigation that brought media attention to the case, for more than five years Federica, Alessandra,

1 Complete data can be found in the journalistic investigation published by R. Ciccarelli in "Il Manifesto" on 4 June 2014, entitled "How to kill a national library". 


\section{T\&F PROOFS NOT FOR DISTRIBUTION}

Work, pensions and transgenerational justice

Laura and Andrea were paid in vouchers: they were given about $€ 400$ for a 24 -hour part-time job. Technically, therefore, they were not workers, yet they worked. They were classified as volunteers of the "Avaca" - Association of voluntary cultural and environmental activities, an association that looked suspiciously like a supplier of skilled labor. The concept of hidden workers, unfortunately, appears in large number of cases. It also applies to those young people who start a traineeship or an internship: in this case the basic idea is that the training comes at a price and that, in some way, the worker must pay for it. The logic is roughly the following: the worker accepts to be paid well below average so that, in exchange, they can receive training in a given area. Sometimes the worker even literally pays to work; more frequently, they accept to work almost for free, because the idea is that the main remuneration lies in the transfer of competences they learn.

These few examples give a good idea of how the forms of work have become, over time, much more difficult to define. In other words, it has become a lot harder to answer a whole number of questions about the nature of work and workers, for example: who really works? And when do they do so? Can we identify specific places assigned to work? Or, again, why do we need to define "volunteers" people who work every day for years on end? Other questions concern the role that institutions play in the creation, protection and reinterpretation of work: for example, why does the state not assume the burden of protecting labour? Why, indeed, does the state very often engage in unreported employment or employment in conditions that are detrimental to personal dignity, as in the case of the "volunteers" for the National Library?

In this regard, despite the fact that the traditional definition of labour has remained substantially unchanged - "a human activity aimed at the production of goods, wealth, or in any case a product of individual or general utility" - two seemingly strange things are happening. On the one hand, the most widespread trend is to remunerate, in terms of money and rights, only highly qualified labor, the kind that cannot be replaced by a machine. On the other hand, there is a tendency to dramatically make unskilled work precarious and undignified, which is exactly what happened to the workers of the National Library and what happens every day to thousands of young interns.

So let's start from here, or rather from the fact that in societies 4.0 the definition of work has not changed, and what has changed, rather, are the places, times and knowledge related to work. As for the places of labour, it is easy to say what's changed: a good internet connection is now all that is needed to work and the workplace can be anywhere. Since work is no longer rigidly bound to defined places, working times have also become more flexible: if the place is changeable, time is completely expandable, provided the work dynamics require it. It is now possible to work from home with a certain ease, and in the not too distant future it will probably be possible to transform even one's car into a mobile and perfectly connected workplace. This is what self-driving cars are pointing to: once driving and transporting passengers are tasks automatically taken care of, cars will end up becoming mobile offices, connected and perfectly equipped. 


\section{T\&F PROOFS NOT FOR DISTRIBUTION}

\section{Tiziana Andina}

While the twentieth century world clearly separated the places and times of work from the places and times of private life, the century we are going through, on the contrary, is characterized by a progressive and, apparently, irreversible blurring of borders: working from home is presented as, and perhaps in some respects is, an opportunity that should allow for greater flexibility. And yet it comes with a downside. The house itself can turn into a vice-office, with working time mixing with the time of personal life. Furthermore, for those precarious workers available to employers on request, home can become the actual workplace. When the boss calls, it is enough to sit in the living room and work from there. It goes without saying that for this type of worker flexibility comes with among other things - a sense of isolation. Flexibility is therefore the keyword, which truly clarifies the dynamics in progress. Places are flexible because technologies are mobile, times are flexible and are less and less linked to places, wages are flexible because they depend directly on the amount of work secured by the worker. So, from a conceptual point of view work remains the same type of thing, but the truth is that, in reality, practically everything has changed. Not for everyone, though - or at least not for everyone in the same way. For example, things are noticeably worse for those who are about to enter the job market - i.e. young people. And, if we fail to reverse this trend, things will be even worse for future generations.

This situation triggers a series of problems in terms of social justice, as it is not uncommon that the labor market presents inequality with regard to the fundamental rights enjoyed by workers. What follows is very often a social structure divided into two large groups: on the one hand, a labor market made up of - often older - workers who can boast a series of rights and protections that safeguard their professional lives; on the other hand, new generations who are very slow to find stability and therefore enjoy no protection or rights of any kind. In addition to being necessarily flexible, young people remain precarious for a long time: in many European countries stabilization is achieved at an increasingly advanced age. I define this phenomenon as "transgenerational inequality", i.e. a permanent condition of injustice between generations that characterizes the contemporary labor market.

Transgenerational inequality in the labor market implies not only that given the same working conditions two individuals may enjoy different rights, but also - in most cases - that some workers (i.e. young people) undergo a significant reduction in welfare, for example in relation to the enjoyment of certain rights or of pension coverage. To be clear, flexible jobs (in time and space) are also those that generally entail reduced access to welfare, despite the fact that these jobs, as with all others, contribute to the collective well-being in terms of general taxation. The thesis that I would like to support is that the cause of this situation of transgenerational inequality - or of an unbalanced relationship between generations for what concerns some important questions of justice - is a deficit of transgenerationality, i.e. a general underestimation of the crucial importance held by transgenerational links and actions within our societies. 


\section{T\&F PROOFS NOT FOR DISTRIBUTION}

Work, pensions and transgenerational justice

\section{What is transgenerationality?}

Political thought has traditionally given a fundamental value to the defense of space: as is known, in fact, the modern state was born exactly through a process of delimiting boundaries and building national identities through separation. The core of this process is fear, which is rightly considered one of the emotions of the political sphere par excellence. Building a barrier that separates us from the other is tantamount to identifying a "we" and to delimiting the space containing this "we" so as to be able to protect it. Lastly, it means leveraging on political and social emotions so that they may take on a positive and active aspect rather than being purely reactional. In the Hobbesian model, the defense of the political space culminates in the delegation of the right to self-defense. At the end of the state formation process, Leviathan has the right and the power to defend the citizens and the space that contains them. Moreover, it has the mission to last in time: whatever happens, Leviathan must last throughout the millennia to come, regardless of any generational change. People and generations pass, Leviathan doesn't - at most it changes in order to last.

A commonwealth is said to be instituted when a multitude of men do agree, and covenant, every one with every one, that to whatsoever man or assembly of man, shall be given by the major part the right to present the person of them all, i.e. to be their representative; every one, as well he voted for it as he voted against it, shall authorize all the actions and judgments of that man, or assembly of men, in the same manner as if they were his own, to the end to live peaceably amongst themselves, and be protected against other men. ${ }^{2}$

Hobbes returns several times to the idea that Leviathan is an indestructible entity, since, ultimately, no one would have the power or the ability to deconstruct it. The basic idea, therefore, is that the state lasts over time because, if it didn't, given the characteristics of human nature, there would be many reasons to fear the return to a bellum omnium contra omnes. Western democracies have equipped themselves with effective tools so that citizens have the opportunity to re-examine some of the foundations and dynamics of common life; nevertheless, the question of duration in time remains crucial, just as the concept of state (or metastate) which underlies the possibility of an institution lasting over time. Hobbes believed that the question of duration was linked to the sole need to guarantee the defense of a population. In reality, in complex societies such as the present ones the theme of durability appears to go hand in hand with the question of justice between different generations.

Lasting means not only resisting, but also implementing types of social actions that envisage transgenerational cooperation: in fact, if, for example, a certain generation incurs a considerable public debt for whatever reason, that debt will have to be repaid at least in part by generations that have neither incurred nor wanted it. In this sense, collaboration between generations is a necessary condition so that 


\section{T\&F PROOFS NOT FOR DISTRIBUTION}

\section{Tiziana Andina}

the fundamental objective - in our example, to incur a debt that allows for a given problem to be resolved - can be reached. Without the reasonable certainty that: (1) future generations will exist; and (2) these generations will agree to keep the commitments made by those who preceded them, there would be no such thing as the public debt of a state, so it would not be possible enjoy in a time $\mathrm{x}$ advantages whose cost we know will be sustained at a time y. The collaboration or, better, the link between different generations therefore lies in things, i.e. in the foundations of the social structure itself.

This being the case, it is evident that there is a question of transgenerational justice to be answered, in relation to decisions and actions that have been made by a group of people - for example by a certain generation - but have significant consequences on the life of different generations. States guarantee the possibility of actions involving a considerable duration in time, since the state, contrary to individuals, has the faculty to last for all the time necessary for a certain action to be carried out. Therefore, it is evident that the questions of justice implicated in this particular performativity are different from those that depend on, or are connected to, the decisions or actions of an individual or of a certain group of people. Based on what we have already said, it is therefore clear that states cannot but pay particular attention not only to the structure of actions that have a transgenerational character, but also to the related questions of justice.

Now, if lasting over time is strategic to achieve the state's objectives, it is also true that what is strategic in theory is not always pursued in concrete political action. The preservation and management of power in Western democracies is an exemplary case in this sense: a central concern in the actions of governments is in fact the maintenance of consensus that, for the most part, comes with actions based on short-term planning. In other words, these are actions that often aimed at obtaining consensus from the voters and follow a short-term logic that is blind to transgenerationality: they do not express the conviction that the correct management of transgenerational relationships and bonds should be among the priorities of a government. This sounds like a real paradox because, as we mentioned earlier, the state's primary concern, by definition, should be to deal with the transgenerational issue.

What emerges, therefore, is an intrinsic conflict, relative to interests and objectives, between state and government: governments, in general, neglect and systematically disregard the importance of the adoption of a transgenerational perspective, favoring, on the contrary, policies aimed at generating and consolidating consensus. Instead, from the perspective of the state, the implementation of policies attentive to transgenerationality is vital both for the duration of the state and for the consolidation of social justice. On this point, therefore, governments and states diverge. Let us try to see why, by first of all trying to understand the nature of transgenerationality; i.e. by trying to understand what we are talking about when we talk about transgenerationality.

So let's try to answer the question: What is transgenerationality?. To understand the nature of transgenerationality it can be useful to start from its opposite, i.e. 


\section{T\&F PROOFS NOT FOR DISTRIBUTION}

Work, pensions and transgenerational justice

from societies that show clear insensitivity to transgenerationality. In these societies, people and institutions have little sensitivity for issues that involve collaboration between generations. In other words, these societies show little or no attention to decisions or actions whose consequences may have wide repercussions on the quality of life of generations to follow. Transgenerationality is therefore a social bond based on a double recognition: the transgenerational relationship that links parents to children (the so-called primary transgenerationality), ${ }^{3}$ but also the bond that unites different generations that belong to the same political place (secondary transgenerationality). However, while primary transgenerationality is a biological constraint, secondary transgenerationality is a social constraint that binds one generation to the other constituting the condition of possibility of the existence of states and metastases: if there were no generational passage, every state would have a duration limited to the life of a generation.

Instead, willy-nilly, generations do collaborate - perhaps, in most cases, it is more correct to say that they make demands in terms of the use of economic resources, natural and environmental resources, and trust. If this is true - and it is - then it is necessary that the political action implemented by the states (we have seen how governments find themselves in a situation of greater difficulty) take into account the fact that the transgenerational constraint exists and indeed is one of the conditions that allows states to last over time. Therefore it must be taken into account not only when a generation makes demands from another, for example claiming rights, but also when it has to respect the duties that come with those rights.

Let's go back to the example of non-transgenerationality. The job market is a rather vague entity - a bit like the art world - composed of multiple actors, whose duties generally vary. Some seek work, some are employed, some have stopped looking for a job, some work by helping others find a job - such as recruitment agencies, private or public companies which continually seek workers, form them and draw from them the human capital they need to achieve their objectives. And many more. The transgenerational bond within the job market takes on at least two forms: that which involves the transfer of competences from one generation to another, and that which involves the "collaboration" between those who work and those who are retired, i.e. those who have worked for many years and are now living on their pension. This pension, as known, is paid for by active workers, according to an exemplary transgenerational exchange.

In this respect, I think it's interesting to consider an old Italian case. It was 1973. The Rumor government issued a provision that would go by the name of "baby pensions": the D.P.R 1092 (see, in particular, article 42). ${ }^{4}$ This provision granted extremely generous conditions for the retirement of certain categories of public employees: 14 years, 6 months and 1 day was the amount of working time needed for married women with children to be able to retire. Other public

3 For a deeper analysis of the issues related to primary transgenerationality, see Schützenberger 1998.

4 For the full text, see http://www.comune.jesi.an.it/MV/leggi/dpr1092-73.htm 


\section{T\&F PROOFS NOT FOR DISTRIBUTION}

\section{Tiziana Andina}

employees had to have worked for 20 years, while local government employees needed 25 years of paid contributions. The anticipated pension opportunity was exploited by around 400,000 people, for an annual expenditure that was estimated to be around $€ 7.5$ billion a year.

The baby pensions were repealed in 1992 by the Amato government, when Italy risked a currency crisis that induced the government to draw up a maneuver based on the revision of the pension system, on the introduction of a property tax and on a general withdrawal from people's bank accounts. The pension directive came with heavy and protracted consequences: there were consequences in terms of expenditure, since a considerable amount of public money was used to pay pensions for people who were still fully productive and who could easily have continued to work for another 25 years, contributing to the country's wealth; and there were consequences in terms of justice between generations, since the following generations, besides having to bear part of the expense to pay for the baby pensions, were subjected to far less advantageous pension treatments, both in economic terms and in terms of rights, for example with reference to their retirement age. In other words, they had to retire much later and got much lower pensions, so as to allow for the sustainability of the system.

The dramatic fact, from a perspective of transgenerational justice, was that the provision had effectively contributed to putting the entire system at risk of unsustainability. In order to continue to allow for early retirement in the long term - i.e. to be able to grant it to future generations as well, as would have been the case from the standpoint of equality - some factors should have jointly occurred: the curve of residents in Italy should have remained positive, and in addition to this, obviously, economic growth should have remained sustained. Instead, the opposite happened: in the 1970s, the growth of the resident population started to slow down substantially until it stopped in the 1980s (see Figure 2.1). The lowest level was reached in 2017 (see Figure 2.2).

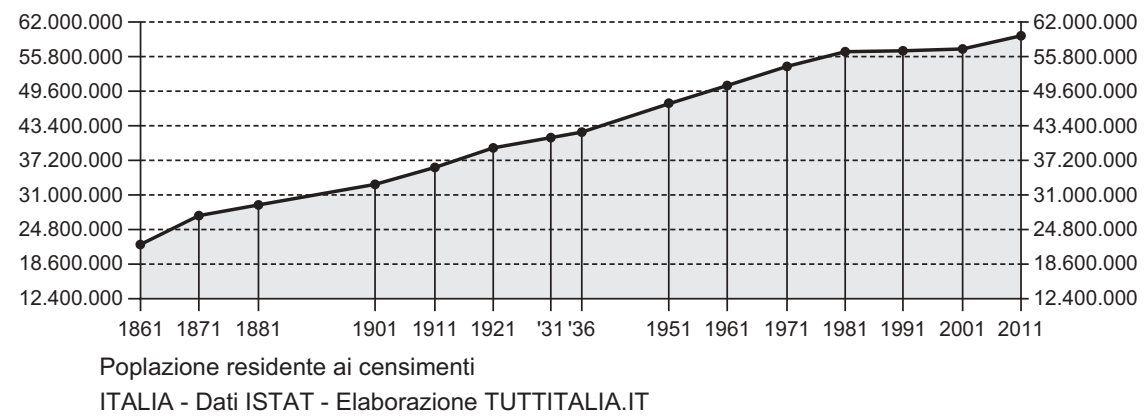

Figure 2.I Growth of the resident population in Italy: I86I-20I I, ISTAT data Note: Resident population trend, ISTAT data at December 3I each year (https://www.istat.it/en/). Source: ISTAT (http://www.programmazioneeconomica.gov.it/2018/12/20/andamenti-lungo-p eriodo-economia-italiana/\#Debito\%20pubblico). 


\section{T\&F PROOFS NOT FOR DISTRIBUTION}

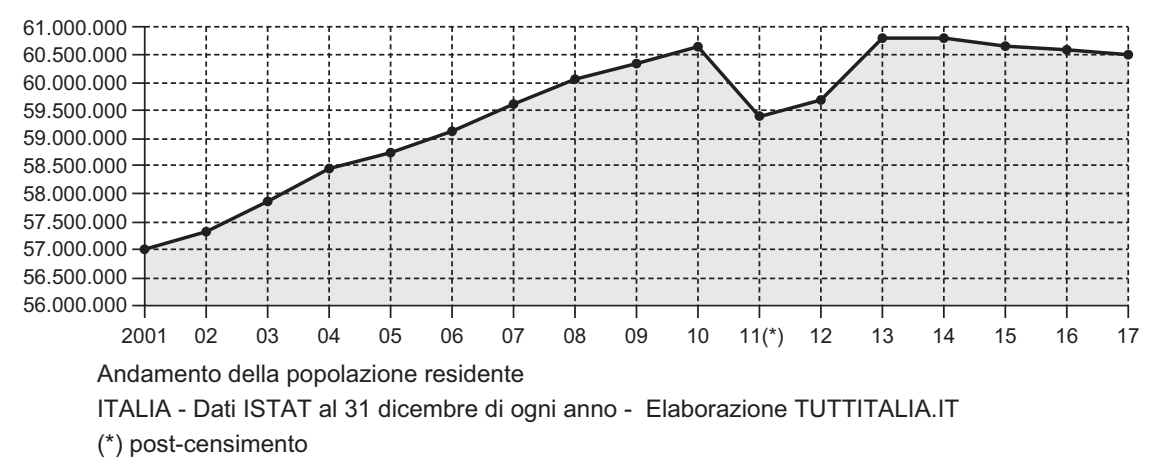

Figure 2.2 Growth of the resident population in Italy: 200I-2017, ISTAT data Note: Resident population trend, ISTAT data at December 3 I each year (https://www.istat.it/en/). Source: ISTAT (http://www.programmazioneeconomica.gov.it/2018//2/20/andamenti-lungo-perio do-economia-italiana/\#Debito\%20pubblico).

The statistical projection of the demographic trend up to 2065 is shown in Figure 2.3.

In this context, the gross domestic product (GDP), as is easy to imagine, did not fare any better: the debt/GDP ratio has been growing steadily from the 1970s until 1994, and has then started to rise again since 2008 (see Figure 2.4). ${ }^{5}$

With regard to the trend of public expenditure in relation to social benefits and pensions, in Figure 2.5, the lower line clearly shows a gradual decrease in employees of the public administration, while the upper line shows a progressive increase in expense items dedicated to social benefits and pensions since the 1980s.

Looking at these data, the situation does not appear to be very promising. In fact, by cross-referencing the data, it can be concluded that since the 1970s the Italian debt has progressively worsened due to high public expenditure (the pension sector being one of the items with significant impact). This was accompanied by a significant reduction in the birth rate, a considerable increase in the age of the population and a progressive reduction in GDP. The question at this point is the following: could all this have been predicted in 1973, at the time of the Rumor provision? As Hans Jonas shows, ${ }^{6}$ when we talk about transgenerational issues - such as pensions - because the consequences of a

5 For an interesting dynamic comparison of the trends of the economies of the main industrialized countries between 1960 and 2017, cf. the World GDP by Country, http://digg.com/video/top-10-countries-by-gdp-1960-2017

6 Cf. Jonas 1984. Jonas addresses the question of the importance of the future for the structuring of social models, focusing above all on the role and potential of technology. The basic thesis, in essence, is this: since technological development has consistently accelerated the human possibilities of intervention on nature, and since technical development has been able to alter the deep balances of nature, humankind must take on the task of making predictions that envision, and prevent, the most negative consequences. For Jonas, therefore, constructing the social world means first of all taking charge of the consequences of social decisions and actions, thereby dealing with the future. 


\section{T\&F PROOFS NOT FOR DISTRIBUTION}

Proiezioni ISTAT sull'evoluzione della popolazione in Italia

(ricostruzione della popazione residente al 1 gennaio fino al 2017, poi proiezioni 2018)

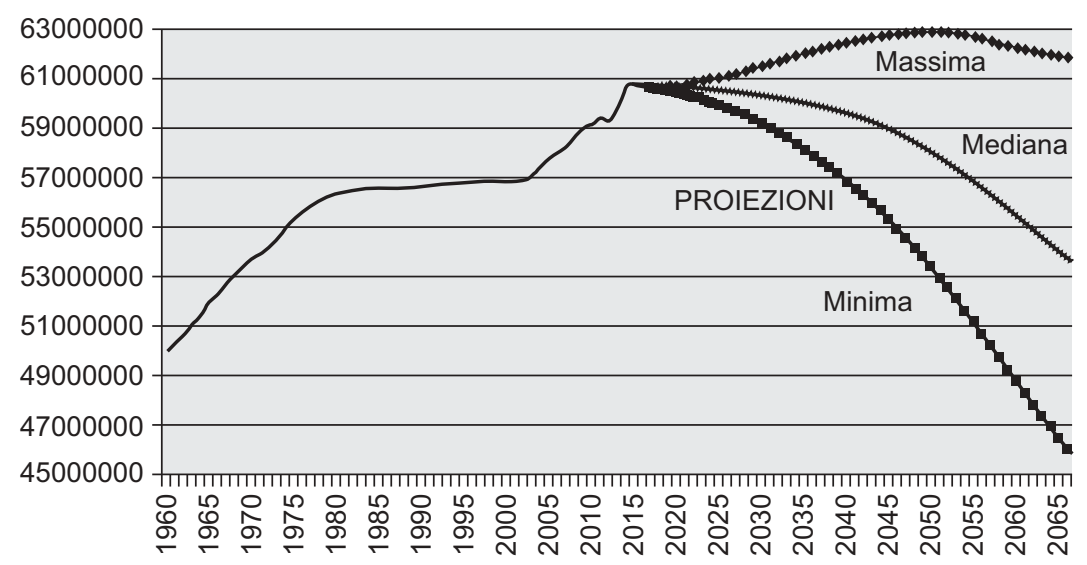

Figure 2.3 Projection of the demographic trend up to 2065

Note: The graph shows the evolution of the total population residing in Italy on I January every year, from 1960 to 2017 (Italians and foreigners), as reconstructed by ISTAT. Starting from 2018, the graph shows three of the demographic projections developed by ISTAT up to 2065: the median is in the middle, between two projections in terms of the highest and lowest possible trends foreseen by ISTAT.

Source: ISTAT (http://www.programmazioneeconomica.gov.it/2018/I2/20/andamenti-lungo-perio do-economia-italiana/\#Debito\%20pubblico).

\section{Italia: \% Debito/PIL} (1861-2015)

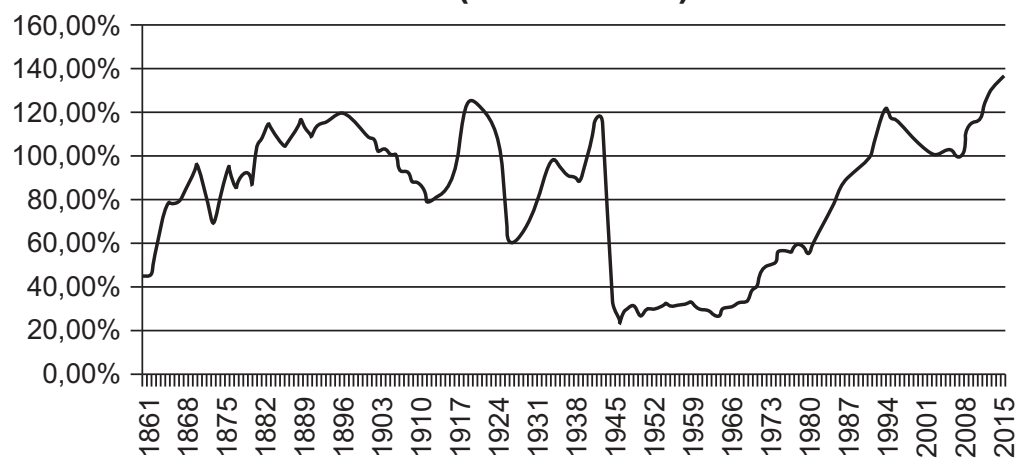

Figure 2.4 Italian debt/GDP ratio (I86I-20I5)

Source: ISTAT (http://www.programmazioneeconomica.gov.it/2018/I2/20/andamenti-lungo-perio do-economia-italiana/\#Debito\%20pubblico). 


\section{T\&F PROOFS NOT FOR DISTRIBUTION}

Work, pensions and transgenerational justice

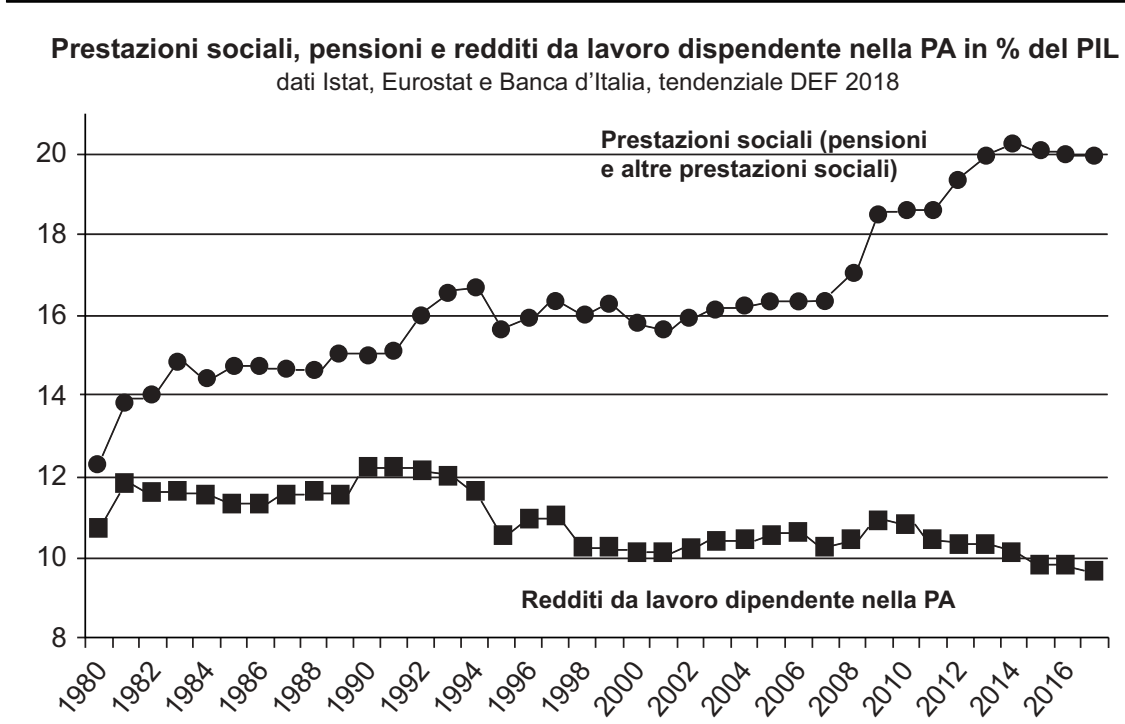

Figure 2.5 Social benefits, pensions and employment income in public administration (percentage of GDP)

Note:The graph shows the evolution of public expenditure on employees in the public administration and the expenditure on social benefits, where the expenditure on pensions is the most significant component.

Source: ISTAT (http://www.programmazioneeconomica.gov.it/2018//2/20/andamenti-lungo-perio do-economia-italiana/\#Debito\%20pubblico), Eurostat, Bank of Italy.

decision in this regard can be seen over a very long time, the worst forecasts must be carefully considered when making any decision. The Italian government, embodied by Rumor and the whole Parliament, did not do so and preferred to make a choice that would guarantee broad consensus to the governing parties. Government and Parliament did not live up to the task of governing for the good of the state, of their fellow citizens and especially of future citizens.

\section{I. Transgenerational inequality}

There are still some considerations to be made on questions of justice - in this specific case, it would be better to say social injustice - raised by this provision. The pension system of a country represents an important piece of the welfare system, which is difficult to keep in balance. When establishing the age for retirement, it is mandatory to think about the consequences of this decision in a dual sense: on the one hand, one needs to think about the sphere of social justice, taking into account the different types of jobs, the degree of labor they require, gender differences and so on. On the other hand, one needs to consider the aim to pursue justice between generations: i.e. parents and children ought to be placed in similar conditions with respect to the rights they enjoy and the duties to which they are subject. 


\section{T\&F PROOFS NOT FOR DISTRIBUTION}

\section{Tiziana Andina}

Now, considering the Italian pension system, one can easily verify the numerous reforms it has undergone. ${ }^{7}$ Let us briefly consider the fundamental stages of this transformation. Social security in Italy was born in 1898 with the aim of protecting workers from invalidity and old age. In 1919 the insurance for disability and old age became mandatory for private employees. The institution of invalidity and old-age pension was introduced, along with compulsory unemployment insurance. Between 1927 and 1941 the Wage Supplementation Fund was introduced, to protect the earnings of people who lost their jobs; the age limit to obtain an oldage pension was increased to 60 for men and 55 for women; the survivor's pension was also established. In the period from 1968 to 1972, the retributive system based on the last salaries received replaced the contributory system. An old-age pension and a social pension were now paid out to all citizens over the age of 65 and below a certain income threshold. In 1992 the minimum retirement age was raised to 65 for men and women, bringing the insurance contribution to 20 years. Starting from 1995 a series of corrections were introduced aiming to calculate pensions based on some principles: the amount of the contributions paid during working life, the expected duration of the pension benefit, and life expectancy.

Starting from the second half of the 1990s, the basic idea was that, while not losing sight of the centrality of the pension system, the increase in life expectancy should affect the ways to calculate the retirement checks. And, in fact, at least in theory, if people do have a greater life expectancy and a better quality of life, they can hopefully remain active in the workplace for longer. This is true at least in general terms, with due exceptions in individual cases or in relation to certain categories of workers. However, despite this general trend, the Rumor government allowed a whole generation to leave the workplace prematurely, setting the conditions to create a situation of true generational injustice, especially to the detriment of those citizens who not could no longer enjoy the same rights (the social composition in the meantime had changed significantly, as the aging of the population meant that people enjoyed retirement checks for a longer time), but who also had to pay for the rights of those baby-pensioners at the expense of their own.

If we assume that an individual has to work for their own and for the collective well-being until the approach of old age, we can agree that the age limit to retire may vary in reference to different factors, but nevertheless should not replace work too early. This is not so much because of some vague paternalism about the idea that humans should prefer work to idleness - indeed, in ancient societies work was left to slaves, while the otium was considered by far the most noble activity since in idleness it was possible to dedicate oneself to one's formation and to cultivate literacy. Rather, more prosaically, it is because a system in which the age of the population grows, the birthrate keeps decreasing and immigration fails to make up for the loss of active population can only be sustainable if people work (and therefore support themselves) for as long as possible. This guarantees that at the

7 Source: INPS, https://www.inps.it/nuovoportaleinps/default.aspx?sPathID =\%3b0\% 3b51646\%3b\&lastMenu=51646\&iMenu=1 1 \&p4=2 


\section{T\&F PROOFS NOT FOR DISTRIBUTION}

Work, pensions and transgenerational justice

appropriate time, i.e. in the phase of life in which they really must be supported through passive income, people can actually be protected. Social justice means first of all protecting those who need it when they actually need it, implementing a reliable system so that this is always possible, for all generations.

\section{Bibliography}

Hobbes, Thomas and C.B. Macpherson. 1968. Leviathan, The Pelican Classics, AC 2. Harmondsworth: Penguin.

Jonas, Hans. 1984. The Imperative of Responsibility: In Search of an Ethics for the Technological Age. Chicago: University of Chicago Press.

Schützenberger, A.A. 1998. The Ancestor Syndrome: Transgenerational Psychotherapy and the Hidden Links in the Family Tree. London: Routledge. 